\title{
Clinical Outcome of Neoplastic Meningitis Associated with Breast Cancer
}

\author{
Anju Anna Abraham ${ }^{1}$ Anoop T.M. ${ }^{1}$ Rona Joseph P. ${ }^{1} \quad$ Arun Vasudevan $^{1}$ Bhavya S. Kumar ${ }^{1}$ \\ ${ }^{1}$ Department of Medical Oncology, Regional Cancer Center, \\ Thiruvananthapuram, Kerala, India \\ Address for correspondence Anoop T.M., MD, DM, DNB, Department \\ of Medical Oncology, Regional Cancer Center, Thiruvananthapuram, \\ Kerala 695011, India (e-mail: dranooptm@yahoo.co.in).
}

J Neurosci Rural Pract 2022;13:108-113.

\author{
Abstract \\ Keywords \\ - neoplastic meningitis \\ - intrathecal \\ methotrexate \\ - leptomeningeal \\ metastasis \\ - survival
}

Background Neoplastic meningitis (NM) is considered as a terminal event with poor prognosis. Its impact in clinical oncology is growing.

Objective To analyze the clinical outcome of patients with carcinoma breast diagnosed with NM.

Materials and Methods This study was an observational study in breast cancer patients diagnosed with NM. Patients with typical clinical symptoms and signs with either presence of cerebrospinal fluid (CSF) cytology positive for neoplastic cells or typical radiological features of leptomeningeal involvement in the presence of neurological symptoms or signs were taken as leptomeningeal metastasis (LM) or NM. The estimation of survival was done by Kaplan-Meier method.

Results Out of 1,200 patients diagnosed with carcinoma breast during the study period, 15 developed NM. The median age of study population was 51 (range: $44-55$ ) years. Most common presentations were headache $(47 \%)$, vomiting $(47 \%)$, diplopia $(20 \%)$, seizure (20\%), and cerebellar signs (7\%). Seven (46\%) patients were hormone receptor positive, four (30\%) were HER2 (Human epidermal growth factor receptor 2) positive and seven (46\%) were triple-negative breast cancer. Median time to develop LM from the time of diagnosis of breast cancer was 6 (range: 3-8) months. Nine patients (90\%) had features of NM in CSF cytology. Thirteen patients received palliative whole brain radiotherapy (20 Gy in five fractions). Nine out of 12 patients received single-agent Capecitabine as first-line chemotherapy after palliative radiation therapy (RT). Intrathecal methotrexate was given for seven patients. The median overall survival was 3 (range: $0.5-4$ ) months.

Conclusion LM is a very aggressive metastatic disease with poor outcome. There is an unmet need for proper guidelines and an overwhelming necessity for a better focus on research for new modalities of disease in this scenario.

\section{Introduction}

Breast cancer is one of the most common cancer-causing central nervous system (CNS) metastases. Eighty percent of brain metastases are parenchymal brain metastases (BM). ${ }^{1}$ Leptomeningeal metastasis (LM) represents only 11 to $20 \%$ of CNS metastasis. ${ }^{1}$ LM is also termed as neoplastic meningitis published online January 11, 2022
DOI https://doi.org/ 10.1055/s-0041-1741505. ISSN 0976-3147.

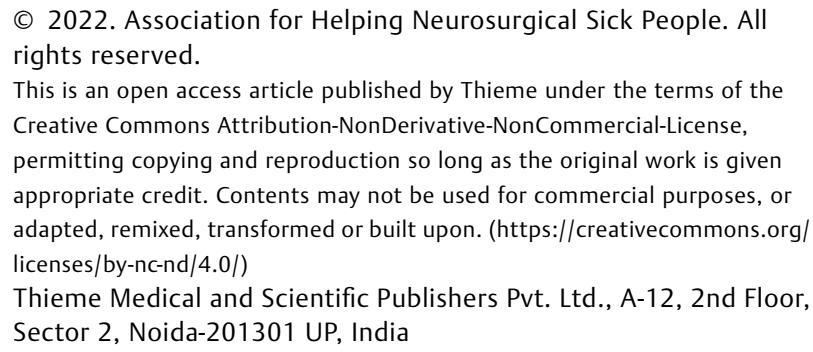

(c) 2022. Association for Helping Neurosurgical Sick People. All rights reserved.

This is an open access article published by Thieme under the terms of the Creative Commons Attribution-NonDerivative-NonCommercial-License, permitting copying and reproduction so long as the original work is given appropriate credit. Contents may not be used for commercial purposes, or adapted, remixed, transformed or built upon. (https://creativecommons.org/ licenses/by-nc-nd/4.0/)

Thieme Medical and Scientific Publishers Pvt. Ltd., A-12, 2nd Floor, Sector 2, Noida-201301 UP, India 
(NM). The detection rates of LM have improved with newer therapeutic modalities, as well as with the advent of newer imaging techniques. ${ }^{2}$ The most common primary tumor metastasizing to the LM is thought to be breast cancer in origin. $^{3}$ Despite novel therapeutic agents, the prognosis of patients remains extremely poor. Here, we describe clinical outcome of patients with carcinoma breast diagnosed with NM.

\section{Materials and Methods}

This was an observational study of breast cancer patients diagnosed with NM, treated in Department of Medical oncology at our Cancer Centre during the period January 2017 to April 2021. Patients received treatment as per institutional guidelines. The baseline characteristics of the patients, diagnostic evaluation, treatment received, outcome, and follow-up details were also collected. Patients with typical clinical symptoms and signs with either presence of CSF cytology positive for neoplastic cells or typical radiological features of leptomeningeal involvement in the presence of neurological symptoms or signs were taken as LM or NM. Intrathecal methotrexate (IT MTX) was given twice weekly for 2 to 4 weeks, followed by weekly once schedule. The dose of IT MTX used was $15 \mathrm{mg}$. CSF cytology was repeated before initiation of each weekly IT schedules and IT MTX continued till CSF becomes clear on two consecutive samples.

\section{Statistical Methods}

Overall survival (OS) was taken time from the date of diagnosis of LM to the date of death from any cause. Progression-free survival (PFS) was taken from time of initiation of treatment to disease progression or death from any cause. The survival was estimated using Kaplan-Meier method.

\section{Results}

Out of 1,200 patients diagnosed with carcinoma breast during the study period, 15 developed NM. - Table 1 shows baseline patient characteristics of this study. - Table 2 shows leptomeningeal variables of this study. All were females. The median age of our study population was 51 (range: 44-55) years. Most common presentations were headache $(47 \%)$, vomiting (47\%), diplopia (20\%), seizure (20\%), and cerebellar signs (7\%). The other presentations included cranial nerve palsies, gait abnormalities, and disorientation. The predominant histological subtype was invasive ductal carcinoma of grade 2 or 3 . The most common T-stage at presentation was T4, seen in seven (46\%) patients. All the patients had nodal metastasis. Eight patients (57\%) had distant metastasis at presentation, with the most common site of metastasis being lungs (29\%). One patient had LM at presentation itself. Seven (46\%) patients were hormone receptor positive, four (30\%) were HER2 positive, and seven (46\%) were triple-negative
Table 1 Baseline patient characteristics

\begin{tabular}{|c|c|}
\hline Variables & Number (\%) \\
\hline Median age $(\mathrm{y})$ & 51 (range: 44-55) \\
\hline \multicolumn{2}{|l|}{ Duration of symptoms (mo) } \\
\hline$<1$ & $2(13)$ \\
\hline $1-6$ & $7(47)$ \\
\hline$\geq 6$ & $1(7)$ \\
\hline \multicolumn{2}{|l|}{ Stage at presentation } \\
\hline Early & $1(7)$ \\
\hline Locally advanced & $6(40)$ \\
\hline Metastatic & $8(53)$ \\
\hline \multicolumn{2}{|l|}{ Initial sites of metastasis } \\
\hline Liver & $3(20)$ \\
\hline Lung & $4(27)$ \\
\hline Leptomeningeal & $1(7)$ \\
\hline Bone & $3(20)$ \\
\hline \multicolumn{2}{|l|}{ TNM stage } \\
\hline \multicolumn{2}{|l|}{ T status } \\
\hline $\mathrm{T} 1$ & $1(7)$ \\
\hline $\mathrm{T} 2$ & $2(13)$ \\
\hline T3 & $5(33)$ \\
\hline $\mathrm{T} 4$ & $7(47)$ \\
\hline \multicolumn{2}{|l|}{$\mathrm{N}$ status } \\
\hline No & $0(0)$ \\
\hline N1 & $4(27)$ \\
\hline N2 & $6(40)$ \\
\hline N3 & $5(33)$ \\
\hline \multicolumn{2}{|l|}{ M status } \\
\hline M0 & $7(47)$ \\
\hline M1 & $8(53)$ \\
\hline \multicolumn{2}{|l|}{ IDC grade } \\
\hline II & $6(40)$ \\
\hline III & $9(60)$ \\
\hline \multicolumn{2}{|l|}{$\mathrm{ER} / \mathrm{PR}$} \\
\hline Positive & $6(40)$ \\
\hline Negative & $4(27)$ \\
\hline \multicolumn{2}{|l|}{ HER2/neu } \\
\hline Positive & $3(20)$ \\
\hline Negative & $7(47)$ \\
\hline Triple negative $B C$ & $4(27)$ \\
\hline \multicolumn{2}{|l|}{ Treatment } \\
\hline Palliative chemo & $7(47)$ \\
\hline Docetaxel & $3(20)$ \\
\hline Docetaxel with trastuzumab & $2(13)$ \\
\hline Hormones alone & $2(13)$ \\
\hline
\end{tabular}


Table 1 (Continued)

\begin{tabular}{|l|l|}
\hline Variables & Number (\%) \\
\hline Adjuvant chemo & \\
\hline Dose dense AC-P & $2(13)$ \\
\hline Neoadjuvant & \\
\hline Dose dense & $4(27)$ \\
\hline AC X4-DOCEX4 + 1year TZ & $1(7)$ \\
\hline Finher & $1(7)$ \\
\hline Surgery & \\
\hline After NACT & $6(40)$ \\
\hline Upfront surgery & $2(13)$ \\
\hline Palliation & $1(7)$ \\
\hline
\end{tabular}

Abbreviations: ACX4-DOCEX4, adriamycin, cyclophosphamide X 4 cycles-Docetaxel $X 4$ cycles; $B C$, breast cancer; ER, estrogen receptor; HER 2, human epidermal growth factor receptor 2; IDC, invasive ductal carcinoma; NACT, neoadjuvant chemotherapy; P, Paclitaxel; PR, progesterone receptor; TNM, tumor $(\mathrm{T})$, nodes $(\mathrm{N})$, and metastases $(\mathrm{M})$; TZ, Trastuzumab.

breast cancer. Patients were evaluated with CSF study and magnetic resonance imaging (MRI). All the patients underwent MRI, among which 11 patients showed leptomeningeal enhancement suggestive of carcinomatous meningitis. A few representative images of LM associated with breast cancer have been depicted in - Fig. 1. CSF study was done in 10 patients and could not be done in the remaining due to threat of ongoing seizure and raised intra cranial pressure. Nine patients (90\%) had features of carcinomatous meningitis in CSF cytology. - Fig. $\mathbf{2}$ shows patient's CSF cytology with clusters of large carcinomatous cells in patients with breast cancer associated NM. One patient had occasional atypical cells only in cytology but had definite MRI evidence of LM. Thirteen patients received palliative whole brain radiotherapy (20 Gy in five fractions). Two patients had very poor general condition and hence radiation was deferred. This was followed by systemic treatment in 12 patients. Systemic therapy and whole brain radiation therapy (WBRT) could not be given in two patients who expired soon after the diagnosis. One patient received only RT and no systemic treatment was given due to the poor general condition. Nine out of 12 patients received single-agent capecitabine. Three patients with HER2-positive metastatic breast cancers received lapatinib plus capecitabine combination. IT MTX was given for seven patients. Two patients are alive now and are continuing on systemic treatment. - Fig. 3 shows Kaplan-Meier curve for PFS. - Fig. 4 shows Kaplan-Meier curve for OS. The median OS was 3 (range: 0.5-4) months. The median follow-up period was 8 (range: 6-14) months. Median time to develop LM from the date of diagnosis of breast cancer was 6 (range: 3-8) months.

\section{Discussion}

LM is often a late finding in cancer. It develops through different ways. The most common ways are hematogenous
Table 2 Leptomeningeal variables

\begin{tabular}{|l|l|}
\hline Presentation & Number (\%) \\
\hline Denovo & $1(7)$ \\
\hline During palliative chemotherapy & $4(27)$ \\
\hline S/P NACT/NACT and surgery & $3(20)$ \\
\hline While on adjuvant & $2(13)$ \\
\hline After completing treatment & $5(33)$ \\
\hline Symptoms & \\
\hline Headache & $7(47)$ \\
\hline Vomiting & $7(47)$ \\
\hline Diplopia & $3(20)$ \\
\hline Cerebellar signs & $1(7)$ \\
\hline Seizure & $3(20)$ \\
\hline Altered behavior & $3(20)$ \\
\hline CSF & \\
\hline Done & $10(67)$ \\
\hline Not done & $5(33)$ \\
\hline Positive & $9(60)$ \\
\hline Equivocal & $1(7)$ \\
\hline CT/MRI & \\
\hline Positive & $11(73)$ \\
\hline Normal & $4(27)$ \\
\hline Treatment & \\
\hline WBRT 20 Gy/5 fractions & $13(87)$ \\
\hline SA capecitabine & $9(60)$ \\
\hline Combination of lapatinib +capecitabine & $3(20)$ \\
\hline No systemic treatment & $3(20)$ \\
\hline Intrathecal methotrexate & $7(47)$ \\
\hline Response & \\
\hline Alive NED & $2(13)$ \\
\hline Expired & $13(87)$ \\
\hline Median PFS & 6 months \\
\hline Median overall survival & 3 months \\
\hline
\end{tabular}

Abbreviations: CSF, cerebrospinal fluid; CT, computed tomography; MRI, magnetic resonance imaging; NACT, neoadjuvant chemotherapy; NED, No evidence of disease; PFS, progression-free survival; SA, single agent; WBRT, whole brain radiation therapy.

spread of tumor, direct extension from bone and brain lesions, or by local spread through the dura. The detection rates of LM are on the rise due to advanced therapeutic strategies leading to improved survival, giving the neoplastic cells the time to reach the sanctuary sites, as most of the drugs used in cancer treatment cannot cross the blood-brain barrier. The use of advanced imaging has also improved the detection rates.

Breast cancer followed by lung cancer and malignant melanoma forms the most common etiology for LM. ${ }^{3}$ However, only $5 \%$ of breast cancer patients develop LM. ${ }^{4}$ Among the various histology, adenocarcinoma has the maximum 

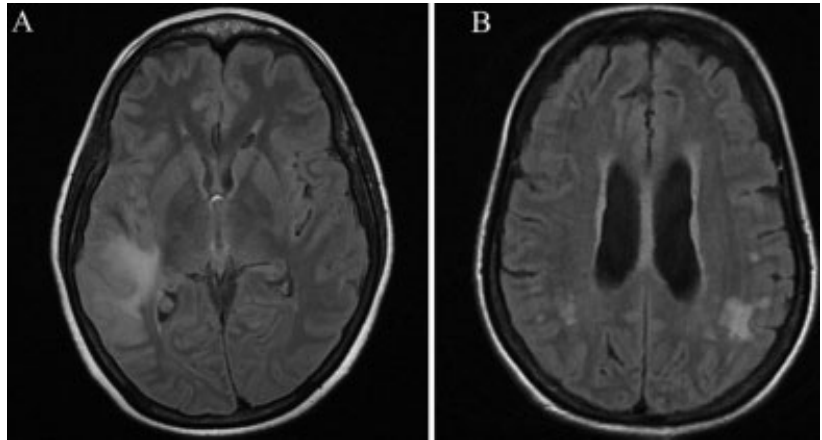

Fig. 1 Images of leptomeningeal metastasis associated with breast cancer. (A) Sulcal T2 FLAIR hyperintensities with leptomeningeal enhancement noted in the right Sylvian fissure and sulcal spaces in the right temporal lobe, extending partly to the parietal lobe. (B) Leptomeningeal enhancement noted in bilateral parietal-temporal regions, more on the left side. FLAIR, fluid-attenuated inversion recovery.

propensity. ${ }^{3}$ Infiltrating lobular histology and triple-negative breast cancer are considered high-risk factors for developing LM. ${ }^{5}$

Signs and symptoms may initially be nonspecific. The usual symptoms are headache, confusion, cognitive impairment, behavioral abnormalities, seizures, cranial nerve deficits, gait abnormalities, radiculopathy, and dysfunction of bowel and bladder. Clinical suspicion of LM should arise in metastatic cancer and can develop typical neurological symptoms. ${ }^{6}$

The imaging modality choice is T1-weighted MRI with gadolinium contrast. ${ }^{7}$ Enhancement and nodularity of the pia, cerebral convexities, basal cisterns, tentorium, or in the

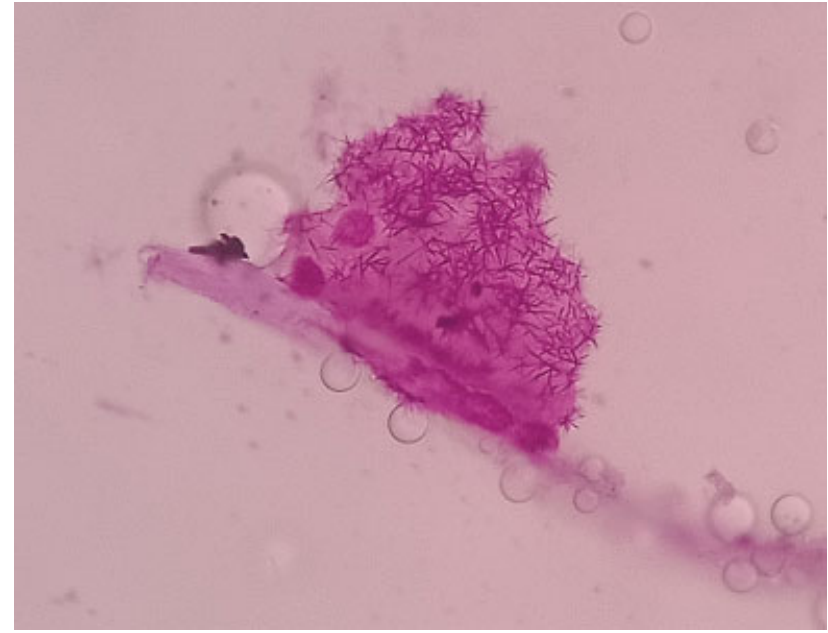

Fig. 2 Patient's CSF cytology with clusters of large carcinomatous cells in patients with breast cancer associated neoplastic meningitis. CSF, cerebrospinal fluid.

ventricular ependymal surfaces are diagnostic of LM. Patchy involvement of nerve roots with occasional matting and intradural extramedullary nodules are seen in spinal imaging. ${ }^{7}$ CSF flow studies using Indium-111 DTPA or Technetium-99m labeled albumin can detect the location of any obstruction in CSF flow as around $50 \%$ of patients can have obstructive hydrocephalus. ${ }^{8}$ The gold standard of diagnosis is CSF cytology which can show neoplastic infiltration in the $\mathrm{CSF}^{9}{ }^{9}$ Repeat collection of CSF increases sensitivity detection to $80 \%$. Other findings in CSF favoring LM include a high CSF pressure, elevated protein, low glucose, and pleocytosis. ${ }^{10}$

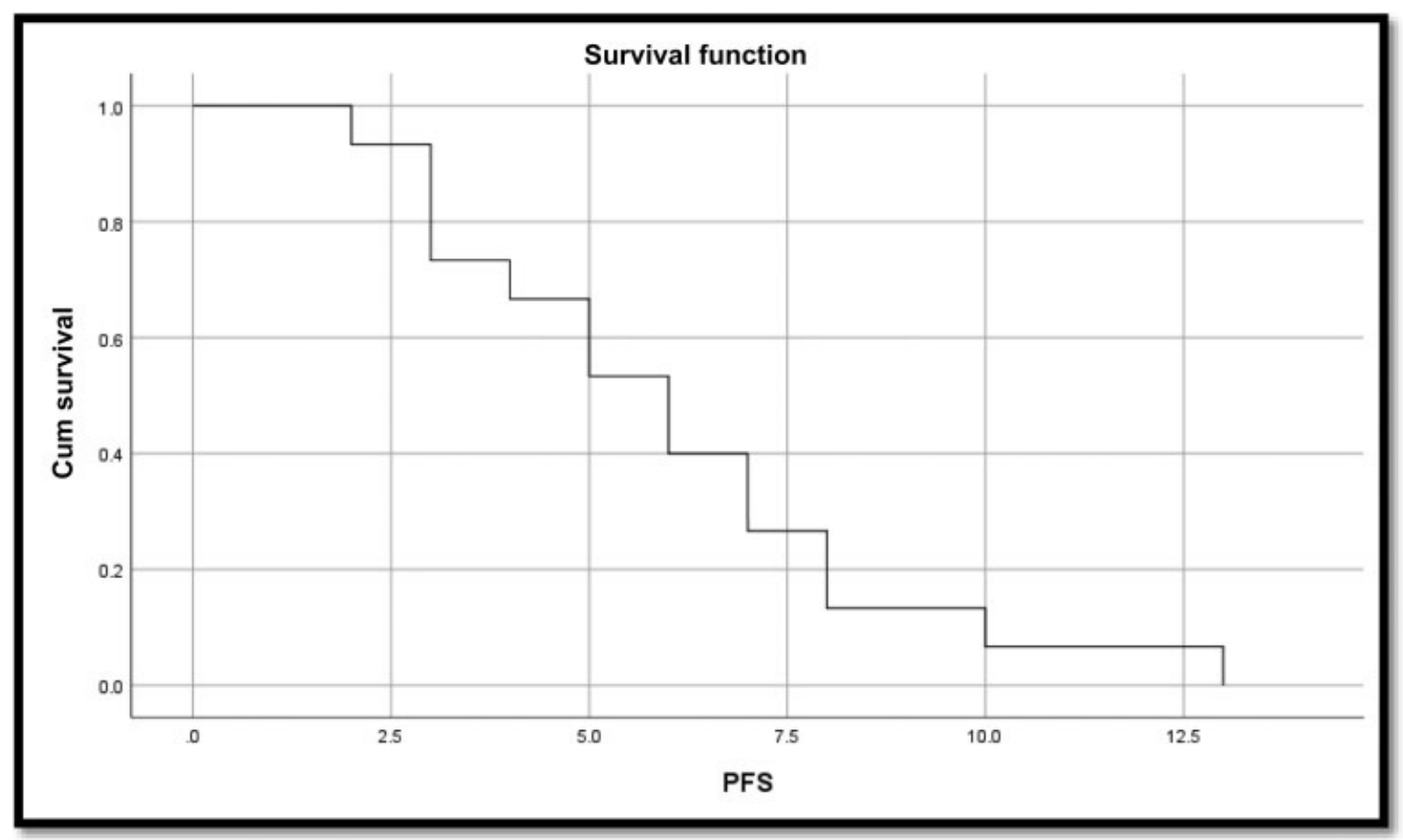

Fig. 3 Kaplan-Meier curve for progression-free survival (PFS). 
112 Neoplastic Meningitis and Breast Cancer Abraham et al.

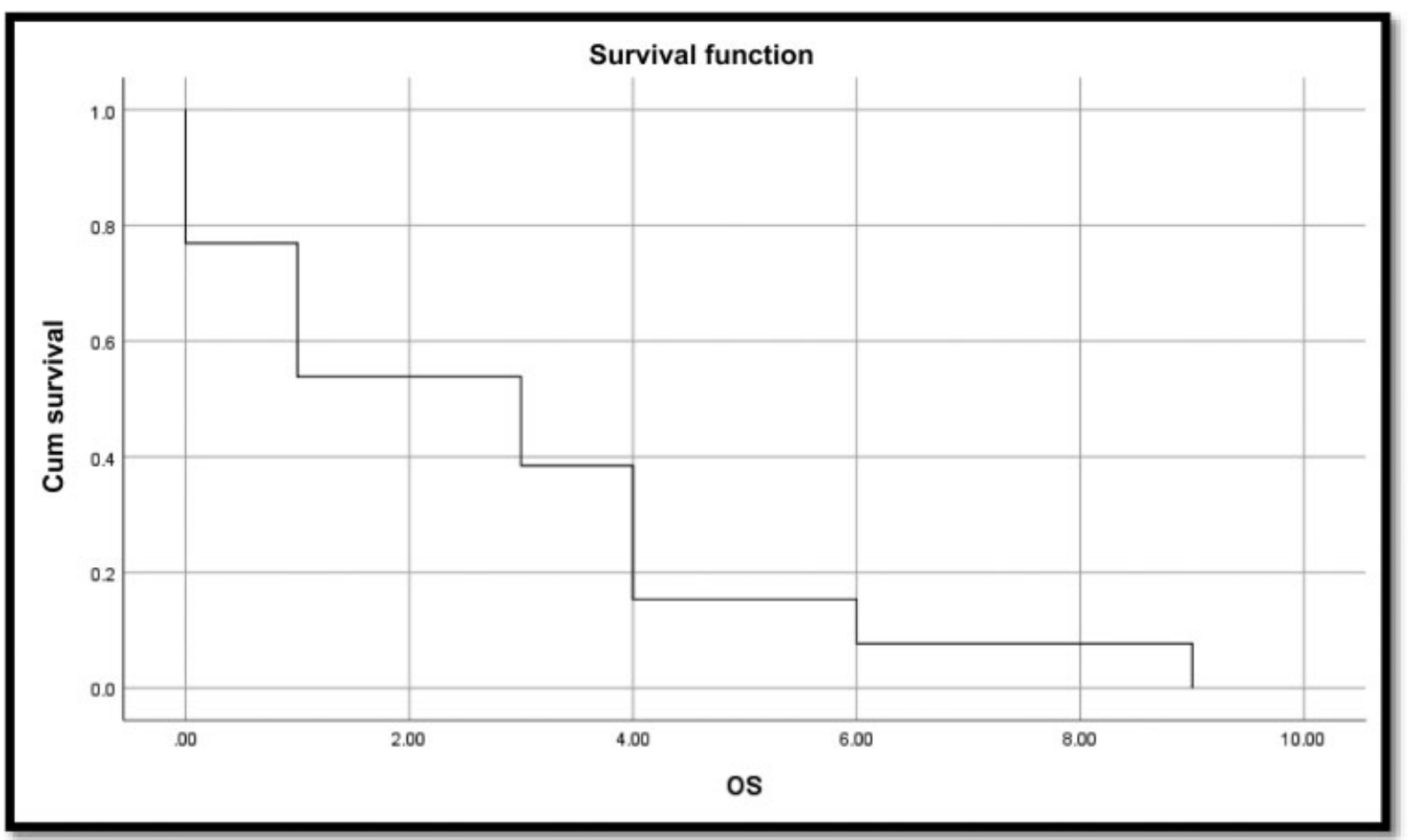

Fig. 4 Kaplan-Meier curve for overall survival (OS).

Table 3 Summary of previous published literature on neoplastic meningitis

\begin{tabular}{|c|c|c|c|c|c|c|c|}
\hline Study (year) & $\begin{array}{l}\text { No of } \\
\text { patients }\end{array}$ & $\begin{array}{l}\text { Median } \\
\text { age }(y)\end{array}$ & Symptoms (\%) & $\begin{array}{l}\text { CSF } \\
\text { positivity } \\
(\%)\end{array}$ & $\begin{array}{l}\text { MRI } \\
\text { positivity } \\
(\%)\end{array}$ & $\begin{array}{l}\text { Risk factors } \\
\text { for LM }\end{array}$ & $\begin{array}{l}\text { Median } \\
\text { OS (mo) }\end{array}$ \\
\hline $\begin{array}{l}\text { Gauthier } \\
\text { et al }(2010)^{12}\end{array}$ & 91 & 53 & $\begin{array}{l}\text { Headache (37) } \\
\text { Cranial nerve } \\
\text { symptoms (27) } \\
\text { Cerebellar signs (26) } \\
\text { Nausea/vomiting (25) } \\
\text { Visual disturbance (24) } \\
\text { Radicular pain (23) }\end{array}$ & 87 & 80 & $\begin{array}{l}\text { Performance status }>2 \\
\geq 3 \text { chemotherapy reg- } \\
\text { imens } \\
\text { before LM diagnosis } \\
\text { Hormone receptor } \\
\text { negativity }\end{array}$ & 4.5 \\
\hline $\begin{array}{l}\text { Niwińska } \\
\text { et al } 2013^{13}\end{array}$ & 118 & 49 & $\begin{array}{l}\text { Headache (54) } \\
\text { Cranial nerves } \\
\text { symptoms (42) } \\
\text { Cerebellar signs (35) } \\
\text { Nausea/vomiting (30) } \\
\text { Mental changes (19) } \\
\text { Meningism (11) }\end{array}$ & 76 & 97 & $\begin{array}{l}\text { Performance status, } \\
\text { TNBC } \\
\text { Lobular histology } \\
\text { Treatment for LM }\end{array}$ & 4.2 \\
\hline $\begin{array}{l}\text { Yust-Katz } \\
\text { et al }(2013)^{14}\end{array}$ & 103 & 49.2 & NA & 90.1 & 86.7 & $\begin{array}{l}\text { Performance status }>2 \\
\text { Negative hormone re- } \\
\text { ceptor status } \\
\text { TNBC } \\
\text { Treatment received for } \\
\text { LM }\end{array}$ & 4.2 \\
\hline $\begin{array}{l}\text { Griguolo } \\
\text { et al }(2018)^{15}\end{array}$ & 153 & 58 & NA & 60.5 & 86.6 & $\begin{array}{l}\text { Performance status }>2 \\
\text { Negative hormone } \\
\text { receptor status } \\
\text { Grade } 3 \\
\text { Positive HER2 } \\
\text { Presence of parenchy- } \\
\text { mal brain metastases } \\
\text { CSF abnormalities }\end{array}$ & 3.9 \\
\hline
\end{tabular}

Abbreviations: CSF, cerebrospinal fluid; LM, leptomeningeal metastasis; HER 2, human epidermal growth factor receptor 2; MRI, magnetic resonance imaging; NA, not available; OS, overall survival; TNBC, triple negative breast cancer. 
Treatment of LM is challenging as there are no definite guidelines to direct therapy. The options depend on the performance status, comorbidities, previous treatment, and sites of metastases. The usual method is to combine systemic treatment with IT MTX with or without the Ommaya reservoir and whole brain radiation. No difference in survival outcomes was seen with one modality over another. Radiation alone has not shown any advantage over basic supportive care. Despite this multimodality treatment, survival is of short duration. ${ }^{11}$

Most of the case series of LM are retrospective in nature. $^{12-15}$ - Table 3 shows summary of previous published literature on NM. The most common biology of breast tumor seen in our study was hormone receptor-positive breast cancer (46\%) which was similar to the data published by Griguolo et al. ${ }^{15}$ Another study by Niwińska et al reported $40.5 \%$ of patients with triple-negative subtype, $37.5 \%$ with luminal-A subtype, and $22 \%$ with HER2-positive subtypes. ${ }^{13}$ The median OS also ranges from 3.9 to 4.5 months as in our case. There are few studies that analyzed the outcomes of LM following administration of systemic chemotherapy. ${ }^{16}$ In our study, 12 patients received systemic treatment in the form of palliative chemotherapy. Nine out of 12 patients received single-agent capecitabine and 3 patients received combination of lapatinib plus capecitabine in metastatic HER2-positive breast cancer. Similarly, administration of systemic chemotherapy after LM diagnosis were associated with prolonged survival. ${ }^{17}$

In a retrospective study, Hyun et al reported that patients with a high Karnofsky's performance status (KPS) or normal CSF protein levels had good prognoses on active treatment. In NM, WBRT may help to restore CSF flow and reduce clinical symptoms. Therefore, it remains a crucial treatment option in the absence of other convincing therapeutic strategies. $^{18,19}$

The ideal duration of intrathecal therapy is still controversial. The drugs commonly used are MTX, liposomal cytarabine (Ara-C), and thioTEPA. Intrathecal trastuzumab in patients with HER2-positive breast cancer LM might be a safe and effective treatment. ${ }^{20}$

\section{Conclusion}

LM is a very aggressive metastatic disease with poor outcome. There is an unmet need for proper guidelines and an overwhelming necessity for a better focus on research for the disease.

\section{Authors' Contributions}

All the authors equally contributed to this work.

\section{Funding}

None.

Conflict of Interest

None declared.

\section{References}

1 Altundag K, Bondy ML, Mirza NQ et al. Clinicopathologic characteristics and prognostic factors in 420 metastatic breast cancer patients with central nervous system metastasis. Cancer 2007; 110(12):2640-2647

2 Frisk G, Svensson T, Bäcklund LM, Lidbrink E, Blomqvist P, Smedby $\mathrm{KE}$. Incidence and time trends of brain metastases admissions among breast cancer patients in Sweden. Br J Cancer 2012;106 (11):1850-1853

3 Nayar G, Ejikeme T, Chongsathidkiet P, et al. Leptomeningeal disease: current diagnostic and therapeutic strategies. Oncotarget 2017;8(42):73312-73328

4 Chamberlain MC. Leptomeningeal metastasis. Curr Opin Oncol 2010;22(06):627-635

$5 \mathrm{Kim} \mathrm{HJ}$, Im SA, Keam B, et al. Clinical outcome of central nervous system metastases from breast cancer: differences in survival depending on systemic treatment. J Neurooncol 2012;106(02): 303-313

6 Chamberlain MC. Leptomeningeal metastasis. Semin Neurol 2010;30(03):236-244

7 Freilich RJ, Krol G, DeAngelis LM. Neuroimaging and cerebrospinal fluid cytology in the diagnosis of leptomeningeal metastasis. Ann Neurol 1995;38(01):51-57

8 Mason WP, Yeh SD, DeAngelis LM. 111Indium-diethylenetriamine pentaacetic acid cerebrospinal fluid flow studies predict distribution of intrathecally administered chemotherapy and outcome in patients with leptomeningeal metastases. Neurology 1998;50 (02):438-444

9 DeAngelis LM, Posner J. Neurological Complications of Cancer. 2nd ed. New York, NY: Oxford University Press; 2009

10 Mack F, Baumert BG, Schäfer N, et al. Therapy of leptomeningeal metastasis in solid tumors. Cancer Treat Rev 2016;43:83-91

11 Le Rhun E, Preusser M, van den Bent M, Andratschke N, Weller M. How we treat patients with leptomeningeal metastases. ESMO Open 2019;4(Suppl 2):e000507

12 Gauthier H, Guilhaume MN, Bidard FC, et al. Survival of breast cancer patients with meningeal carcinomatosis. Ann Oncol 2010; 21(11):2183-2187

13 Niwińska A, Rudnicka H, Murawska M. Breast cancer leptomeningeal metastasis: propensity of breast cancer subtypes for leptomeninges and the analysis of factors influencing survival. Med Oncol 2013;30(01):408

14 Yust-Katz S, Garciarena P, Liu D, et al. Breast cancer and leptomeningeal disease (LMD): hormone receptor status influences time to development of LMD and survival from LMD diagnosis. J Neurooncol 2013;114(02):229-235

15 Griguolo G, Pouderoux S, Dieci MV, et al. Clinicopathological and treatment-associated prognostic factors in patients with breast cancer leptomeningeal metastases in relation to tumor biology. Oncologist 2018;23(11):1289-1299

16 Du C, Hong R, Shi Y, Yu X, Wang J. Leptomeningeal metastasis from solid tumors: a single center experience in Chinese patients. J Neurooncol 2013;115(02):285-291

$17 \mathrm{Kim} \mathrm{H}$, Lee EM. A Retrospective analysis of the clinical outcomes of leptomeningeal metastasis in patients with solid tumors. Brain Tumor Res Treat 2018;6(02):54-59

18 Hyun JW, Jeong IH, Joung A, Cho HJ, Kim SH, Kim HJ. Leptomeningeal metastasis: clinical experience of 519 cases. Eur J Cancer 2016;56:107-114

19 Roth P, Weller M. Management of neoplastic meningitis. Linchuang Zhongliuxue Zazhi 2015;4(02):26

20 Zagouri F, Zoumpourlis P, Le Rhun E, et al. Intrathecal administration of anti-HER2 treatment for the treatment of meningeal carcinomatosis in breast cancer: a metanalysis with meta-regression. Cancer Treat Rev 2020;88:102046 